\title{
Sports to Improve Education in Brazil from the Perspective of Students
}

\author{
Antônio José Müller \\ Fundação Universitária Regional de Blumenau- SC \\ Rua Antônio da Veiga, 140 \\ Email: antoniomuller2 [AT] hotmail.com
}

\begin{abstract}
In many countries around the world, school considered an essential factor for the development of children, young people, citizens and the country as a whole. However, in developing countries such as Brazil, the number of dropouts is very high. Many issues contribute to this reality: from student malnutrition and persistent social stratification to inadequate links between the school and the students' outside environment. Sport is a cultural expression that most people appreciate and it could best used as a motivating tool for keeping students in schools. From this, this research aims to understand how sport can play its role in the effective contribution of promoting social inclusion and academic motivation. Participated in the exploratory qualitative study 14 male and female students from two schools, one public and one private, high school, using structured interviews seeking to identify how the sport established in relation to academic motivation and social inclusion in lives of these students.
\end{abstract}

Keywords-Capital of the Body, Sport at school, Academic motivation, Social Inclusion Sport in Society, Education and sport.

\section{INTRODUCTION}

In Brazil, according to 2016 School Census data, 2.8 million children and adolescents from 4 to 17 years old are out of school. Most of this population is between 15 and 17 years old, considered suitable for high school. There are almost 1.6 million teenagers without attending classes. In addition, there are a large number of students who are part of the Failure Rate (Sum of Failure and Abandonment), reaching 36.6\% in Grade 1, 16.4\% in Grade 2 and 10.5\% in Grade 3. High School [1]. Students are out of school or unmotivated with the educational process for many different reasons, such as economic problems, social problems, or curriculum-related problems. One of the possibilities for reducing these problems and making the school more attractive is in the interest of the students in matters related to their culture, especially the sport and its practice. Some children prefer to engage in sports or music as opposed to education participation. Instead of being in school and gaining academic knowledge and skills, they prefer to be playing because it is so much more interesting than going to school. Many reasons lead us to drop out of school. However, they do not give up on sports. This link between sport and society could further explored in schools as a factor of academic motivation and social inclusion. Sport, as a pedagogical instrument, needs to integrated with the general purposes of education, the development of individualities, the formation of citizenship and the orientation of social practice. The pedagogical field of sport is an open field for the exploration of new meanings / meaning, that is, it allows them to explore the action of the students involved in different situations [2]. Thus, it is essential to understand the influence of sport on students' lives to identify how sport is present and how it can used in motivation and social inclusion in education.

Significant research describes the importance of sport in entertainment, in improving health and in people's lives, especially in schools where sport is inherently beneficial to youth for its potential contributions to social, psychological, physical and ethical development [3]. However, only a few studies identify sports support structure and practices as a social and academic promoter. Moreover, there is no articulated link between society and school with sport to relate research into practice. While a good deal of literature deals with sport and society, they relate predominantly to the concept of high-level competition and cooperation (teamwork and leadership). Few studies offer a conceptualization for sport linked to education from a cultural perspective in order to understand and demonstrate how sport can play its role in effectively contributing to the promotion of social inclusion and academic motivation. In addition, there is an urgent need for school reforms in curricular and pedagogical issues. Therefore, the behavior of at-risk students must be addressed and the proper connection between the school and the students' outside environment. [4]. Found a relationship between sports participation and dropout rates and advocate participation in sport as a means of developing a positive connection with school. Regardless of social, gender or racial background, participation in sport can keep students in school and avoid 
downtime problems such as drugs, violence, pregnancy, boredom, obesity and a lifelong orientation to well-being. Because sport is a subject that many young people enjoy, schools should increase student participation in sport to promote and expand educational opportunities. Since sport can be used a vehicle of educational and social opportunities.

Sport is a social model that is part of the educational experience during childhood and adolescence until adulthood. It organized according to the social and cultural values where it develops. However, the great difficulty is to understand how this formative benefit can inserted and amplified when related to education. This study aims to identify potential policy and practice alternatives, such as student participation in sports related to satisfactory academic progress, in order to offer options that support and promote learning opportunities in accordance with cultural and economic differences. The use of certain social influences may be subject to further investigation because of new knowledge and understanding of sporting opportunities. Finally, the current discussion on sport and social inclusion must viewed from a broader perspective to understand how less privileged socioeconomic groups can receive benefits through sport.

This study will also identify potential policy and practice alternatives, such as student participation in sports related to satisfactory academic progress, in order to offer options that support and promote learning opportunities in accordance with cultural and economic differences. The use of certain social influences may be subject to further investigation because of new knowledge and understanding of sporting opportunities. Finally, the current discussion on sport and social inclusion must viewed from a broader perspective to understand how less privileged socioeconomic groups can receive benefits through sport. Sports at school should be a motivational factor in keeping students and, even more, motivating them academically during the school years, thus reducing the number of dropouts and retention between grades / age matched.

The main objective of this paper is to understand how sport can play its role in the effective contribution of promoting social inclusion and academic motivation. The other objectives are: (1) to compare the contemporary situation of sport related to education; (2) Identify the variables that influence sports participation in high school and its relationship with school performance and social inclusion; (3) contextualize new teaching possibilities through sport.

\section{SPORTS IS SCHOOL}

Historically, sport has become a popular expression of culture. The concept of sport is not just excitement, fanaticism and enthusiasm, but also social participation where economic, political and educational impact is included. Moreover, for many poor or segregated people, sports appear to be one of the few opportunities allowed and available for success in a perceived oppressive racist society. Sport is one of the most important sociocultural phenomena in the world. In fact, the social importance of sport related to the significant development of the athletic movement, increasing the number of people participating in and watching the spectacular world of sport. The phenomenon of sport influences millions of people around the world. Most people enjoy playing, watching and discussing a variety of sports. Sport occupies a prominent place in different cultures and has significant social influences. According to [5], sport is a significant form of social activity, and sport affects the educational system, the economy, and citizens' values. Especially today, sport has enormous impact and social significance. Snyder and [6] summarize that the phenomenon of sport grew in the twentieth century to become one of the most widespread social creations in contemporary societies. Its social significance, when linked to education, through participation and performance can interpreted as a distinctive democratic opportunity for humanity as a whole. At least at the sport participation or leisure level, people with some exceptions, with or without talent, of any economic social status, even with physical limitations can participate and enjoy the benefits of sports. Sport may be a part of the democratic system through eventual participation of the population at all ages, genders and levels and may reflect social inclusion and motivation. In addition, sport can provide a basis for socializing minorities or disadvantaged classes. For many poor people, sport appears to be one of the few opportunities allowed and available for success in racist and oppressive societies [7].

For [8], playing sports is fundamental to the development of all girls and boys, as it increases learning capacity, develops other skills and offers children and adolescents more opportunities for healthy living.

Sport has a great influence on a person's life, developing personality and character and, consequently, contributing to good citizenship [9]. The benefits are significant for children and adolescents, as physical activity and sport are crucial for physical, social, motor and emotional development. With this in mind, sport benefits cultures in childhood and lifelong health; in the area of learning and academic achievement; in the areas of citizenship and democratic access; And in the areas of leadership and motivation. For example, in sports, adolescents may learn valuable skills related to quality of life: intrapersonal and interpersonal communication, determination, perseverance, trust, leadership, citizenship, goal orientation, motivation, and personal satisfaction [10]. There is an importance of sport as indispensable for the permanent education of people [11]. Socialization must be a factor present in physical education. The sport captivates, engages and brings people closer, because it has a "magic" that revolves around itself [12]. In order to pursue academic motivation and social inclusion, physical education should offered to our students that provides opportunities for growth, not as a 
moment of exclusion and detachment from sports practices, leading to non-socialization and exclusion. The same sport that attracts so many also excludes, because not all had good learning and coexistence through it [12]. The social opportunities inherent in most sports enable individuals to develop social relationships and feel part of a group in pursuit of a common goal, as a positive result of common work and effort. These social opportunities are relevant to the sports experience as they can increase participants' motivation for other areas of activity. However, the implications of the desire for social connections, the goal-oriented behavior that may result, and the perceptions of belonging help explain motivation in sport, but are not well understood [13]. Children dream of being able to participate in professional sports, but few enjoy this benefit. Through sports, large numbers of people could helped to change their lives for the better.

Despite its benefits, sport, like school, is as much an achievement as a social domain or as detached from school. A possible link between student interest and school affairs may be the culture-oriented curriculum. Curriculum must respect the cultural background that students bring when they go to school. As [14] says: "Why not establish an" intimate "connection between the knowledge considered basic to any school curriculum and the knowledge that is the result of the experience of these students as individuals? The curriculum has the potential to increase motivation as it can take advantage of student life experiences and encourage students to be present and participate in the learning process that could make the school an authentic place for "student-centered instruction." The development of change-responsive programs there must be a connection between what children practice and enjoy with what taught in the school curriculum, and a variety of activities that closely relate to the customs and traditions of local life and culture should be incorporated [15]. In addition, the curriculum can promote and foster interest in education in unmotivated communities, where and students do not realize the importance and relevance of school, as it represents a different world from the reality in which they live daily. The school must be connected to a student's local culture in order to develop a universal culture, which is the combination of social, individual, physical and mental development .[16] explains that when children arrive at schools, they bring with them an understanding of the world, in different dimensions and according to their social class. The places they come from and the cultural context in which they live are the beginning of their knowledge bases.

To this end, Freire was convinced that a curriculum for student achievement should be a process of analyzing reality so that they could become critically aware of their situation. Some children may not see the connection between classroom activities and their daily lives. Sport is an important subject in the lives of some students, which could promote academic opportunities for them. This connection must take into account forms of oppression, as the ruling class can manipulate the population by teaching what it wants to keep people immobilized by the ideology of fatalism - adapting the student to what is inevitable and cannot changed. This may be a Freirean utopia, but if education cannot do the whole thing, there is something fundamental it can do. If education is not the key to social transformation, it not intended to reproduce the dominant ideology either [14]. The school curriculum could be prepared to change this fatalistic historical ideology and critically educate students. From this perspective, the curriculum is about optimism and hope that can expand curiosity, creativity and imagination. It refers to the general critique of Freire's education. He argues that any curriculum that ignores racism, sexism, the exploitation of workers, and other forms of oppression at the same time supports the status quo [17]. Ignoring marginalization inhibits the expansion of consciousness and blocks the creative and liberating social action for change.

\section{METHODOLOGY}

This research is qualitative and exploratory - to generate hypotheses for future research - and descriptive - to identify plausible relationships that shape the phenomenon of interest [18]. The main objective of this study is to understand how sport can play its role in the effective contribution of promoting social inclusion and academic motivation. These issues investigated using conventional library sources, placing strong emphasis on the interpretation and analysis of primary sources. Thus, the study begins with a review of the literature related to the history and culture of sport in our society to support and bring to light the social importance of sport. Examine the literature to determine how sport influences communities and students. It examines how sport applied in schools and how students understand its importance in their lives. This research covers the use and collection of a variety of materials - personal experiences, interviews and observations - that "describe routine and problematic moments and meanings in individual lives" [20].

Using interviews, narratives and observations with regular students and students / athletes, as methods of collecting qualitative data in high schools that volunteer to participate in the study. This collection of information can provide other voices to look at the influence of sport, seeking to identify how sport established in relation to academic motivation and social inclusion in students' lives. Student selection was determined the comparative nature of the study and will cover both male and female students / athletes from public and private schools in Blumenau.

The study included 14 male and female students from two schools in Blumenau, SC, a private school and a public high school. My intention was to let the values of the participants guide the study because the interviews conducted will allow investigating the student and student / athlete experiences that the researcher can consider to reveal reality and 
explain the truth [20].

The interpretation of the data will be rooted in critical hermeneutics. My ideological perspective based on Freire's theories, where I can explore the meanings of social life, the historical problem of domination, alienation, and social struggle, a critique of society, and the vision of new possibilities [21]. The qualitative analysis of the information began by looking for themes that emerged from the participants. The act of collecting, reading and organizing data served as the first phase of analysis. A primary method of qualitative analysis is through unit organization and unit aggregation into emerging categories. The analysis performed to provide verification and authenticity of the influences created by the sport. Finally, an interpretation of the analysis been made for a global or expansive understanding of sport, society, and education, which will be best, understood by the contribution of critical hermeneutics. Since hermeneutics based on an interpretive approach as a tradition of inquiry and seeks to understand a larger picture by understanding a smaller picture, the "critical" aspect allows this research to take what the subject says and deconstruct his or her tendencies. Hegemonic ideological values [22].

For the purposes of this paper, a comparative study between schools and students from public and private institutions is considered. The idea is to analyze specific questions in these two realities to compare their manifestations in different sociocultural contexts (schools, customs, traditions, and lifestyles), using the same research tools to perform a secondary analysis of national characteristics and data of school performance to perform new comparisons. Thus, I can seek explanations for similarities and differences, generalize from them, or gain a greater understanding of reality in different social contexts [23].

\section{DATA GENERATION}

Data generation took place in two schools in Blumenau, one private (Bom Jesus Santo Antonio) and one state public school (EEM Prof. Elza Henriqueta Pacheco). Elza Pacheco School operates in the same space for basic education, as a municipal school and with the name of BSE Victor Hering. The initial contact made with both principals of the referred schools, through an office and later with the Physical Education teachers responsible for High School, indicated by the direction. At Bom Jesus High School, a request also made to the coordinator of the Physical Education department who recommended contact with the specific teacher. Thus, both teachers selected students / athletes to form a focus group and then conducted the interviews at a time and place determined by the teachers. At Elza Pacheco School, the group consisted of 6 students, two female, one of volleyball and one of athletics and four male, three of soccer and one of judo. At Bom Jesus High School, 8 students were interviewed, 5 male and 3 female. Of these, 5 play basketball, two play rhythmic gymnastics and one plays handball, all on the Municipal Sports Foundation (FMD) teams. Of these 4, they receive scholarships to attend college, with a reduction in tuition fees. Students represent the municipality in state-level events such as the Santa Catarina School Games (JESC) or Open Games. Football students train in the Metropolitano team and participate in regional and state events of this type.

Figure 1: Interviewee Description

\begin{tabular}{c|c|c|c}
\hline \multicolumn{2}{c|}{ Private school } & \multicolumn{2}{c}{ Pchool } \\
\hline Name & Age & Name & Age \\
\hline Pedro & 17 & Marco & 16 \\
Bernardo & 16 & Daniel & 16 \\
Bruno & 17 & Amanda & 15 \\
Ana Júlia & 16 & Isabel & 14 \\
Sandro & 16 & Juliano & 16 \\
Douglas & 16 & Gustavo & \\
Cećlia & 15 & & \\
Raquel & 15 & & \\
\hline
\end{tabular}

Table 1: Data from public and private school students interviewed.

The researcher developed a script of questions that used at the time and from this script, new questions presented, with the objective of the students to express their opinions freely and frankly. The researcher also observed the students' behavior, thus seeking greater reliability of the answers and personal characteristics that may interfere with the research.

In both schools, the researcher gave a brief presentation of the research objectives and informed students that they would not have their names revealed. The questions related to sport, education, and its relation to academic performance and inclusion and social behavior. The groups gave opinions at random and freely. At times, the researcher encouraged everyone to give their opinions and tried to delve into issues of greater interest or that left doubts of interpretation. The 
comments were audio recorded by the researcher and will be transcribed in text in the next step of the research. The interviews took place only once in each group / school, were uninterrupted and lasted approximately one hour each.

I began each interview with a common question: "Talk about sports" and developed the following questions according to the participants' answers. I explored their opinions and kept the conversation focused on sport in their schools and lives. I conducted semi-structured interviews lasting 30 to 45 minutes in each group. My concern was to interview without directing the participant to a particular way of thinking or a particular set of reactions and responses. I encouraged participants to give "freedom of expression" without any concern for school administrators or teachers.

In the data analysis stage, the categories will presented with the appropriate discussions and opinions that confirm the categories themselves and thus we can reach an evaluation and conclusions that should reach the initial objectives of the research. The interviews transcribed to the text, but only the opinions considered relevant, thus, some of the students interviewed do not appear in the narrative descriptions.

\section{DATA ANALYSIS}

Using interviews, narratives and observations with students / athletes from Freire's perspective, I formed the methods of qualitative information gathering to support and bring to light the social importance of sport. This qualitative collection of information provided other voices in analyzing the influence of sport on students' lives to identify how sport was established and how it can used as academic motivation and social inclusion.

Public schools are predominantly compo sed of low-income students, as opposed to public schools; private schools are predominantly for high-income students; therefore, I had to choose a private school for research application. I chose to interview high school students because they were participating in regular and practical sports competitions, attending regular classes, and had time to discuss academic, professional and sports expectations.

From the interviews, some initial observations and conclusions can made and then analyzed in depth in categories. Being exploratory research, what most relevant that: student athletes are very popular in schools; everyone is delighted to be playing sports and cannot imagine themselves out of it; everyone agrees that it is difficult to reconcile studies with training; that the school should have more sports; that school should be more interesting; and that physical education should be more attractive. As this is a comparative research, the most relevant initial considerations were: public school students do not care about the level of education they receive as much as private school students; Public school students consider sport a form of work and most of them want to be a professional athlete as adults. On the other hand, private school students use sport to improve their learning condition and do not want to be athletes as adults. Private school students complain about the intensity of the school's activities and obligations, while public school students complain about the neglect of some teachers and even sports and physical education teachers. Other relevant questions arose in relation to the type of sport practiced and what could observed is that students who practice individual sports such as judo and athletics are less explicit than those who practice collective sports such as basketball, soccer and volleyball.

The transcripts of each interview and field note generated new categories or themes expressed by the participants. As categories of meaning emerged, the researcher sought those that had internal convergence and external divergence [24]. Subsequently, the emerging categories and themes compared with each other. The themes emerged and presented as the most relevant in the question of motivation or inclusion, as follows:

\subsection{Public School Student Themes}

Unprepared Teachers - What we noticed in this item is that public school students have less enthusiasm and interest in school, yet they show more criticism in their comments about education. The biggest criticism relates to the lack of preparation and lack of enthusiasm of teachers. Marco, a 16-year-old basketball player, said:

Teachers are not motivated and not ready for class. They come with the book, and that is for today and that is all. I think they are not motivated because they received a low salary. They come stressed to school and have their particular problems. Then they come to teach and direct their anger at the students all morning.

Teachers are not motivated and not ready for class. They come with the book, and that is for today and that is all. I think they are not motivated because they received a low salary. They come stressed to school and have their particular problems. Then they come to teach and direct their anger at the students all morning.

Using this statement, I explored interviews asking what could best used in school and sports to improve education. Daniele, a 16-year-old handball player, said: "I think sports and education should go together stimulating each other." Therefore, I asked how we could do this, and she said, "I think it would start with the teacher. We need teachers to stimulate students, more extracurricular activities and an increase in the number of hours at school." Sports is a topic included It should also be included in the curriculum through interdisciplinary studies, where each subject explores the same topic but in a different area of interest. Isabel mentioned, "You have many different situations in sport, and you put 
that situation sometimes in practical situations in your life." Sport could be included as a cultural generating theme and thus a factor in stimulating learning.

To understand how theory can related to practice, or how sport can used in regular classes, I asked participants, and Daniel said, "Why don't teachers explore the subject better?" I asked, "Like what?" He said. "In physics, for example, we can see through the ball and see... prove the theory with the ball, speed, high and distance... pure physics..." I thought it was a great idea. Using sports in regular classes, many things could connected to interesting aspects of learning. Your idea can used to narrow the gap between theory and practice.

The better this process, the theory is identified with practice, the greater the gain in intelligence and the greater the possibility of stimulating epistemological curiosity and creativity. This pedagogy is the pedagogy of freedom as [14] points out that a democratic teaching practice should reveal in its relation the freedom of students towards their own selfconfidence. Self-confidence, however, must be present in teachers and be based on professional competence, as "teachers are not motivated".

I asked why good practice is not happening in class, and Marco replied, "Some students are not motivated, teachers are not creating attractive classes either." Students are not motivated because of teachers. Teachers should create opportunities by combining theory and practice, making the school more interesting.

School is boring - Most participants mentioned that school is not an exciting place to be, especially public school students. His major concern linked to the lack of options that would make the school more attractive. Daniel compared the situation of his public school with the best situation in private schools. He said:

In private schools... you have computer class, the next day you have music class... surely in private school they have. Here the classroom is overcrowded, lacking space, and if you are sitting in the back seat, you never hear what the teacher is saying.

Problems in public education in Brazil linked to lack of investment, mismanagement and social inequality. These problems almost disappear in private education for the simple reason that more resources are available that turn private schools into institutions with admirable qualities. Student / athletes said the school is boring for regular students. Athletes mentioned that their routine is better and it seems that they have more enthusiasm and better behavior in school compared to non-athletes. Amanda 15 years old, volleyball player, said:

Wake up in the morning, go to school, come home, sleep all day, do not waste energy, do not use time for anything, and go back to school... boring routine. Regular students stressed because they do not waste energy those who do not do the sport, start to make noise, make a mess in the classroom.

Through interviews, I realized that sports students believe that education is important and have more respect for teachers. Perhaps, because they feel the harmony between authority and freedom, discipline necessarily implies respect for each other [14] as they learn in sport. Students can develop theory in practice because in each game or practice they confronted with new and different situations in this very dynamic, spiral and infinite process. As Isabel assumed:

I started playing and now I feel better at school. However, school is not as fun as sports. I do not know how, but in sports, I am learning to change for the better. I do not know how, but my grades are better now after I started playing.

She is just an example, but she believes her improvements in studies were because of sport, and she also assumed that school was less boring with sport. The school is boring because it stipulates many theories that are promoting circles of potentially oppressive hierarchy [25].

Sport Helping Education - The theory that sport can help education is important but not very clear. Sports education used regularly in schools in different countries to provide integral and complete development through physical-cognitive connections.

During the interviews, many points explained the connections and benefits of sport as an academic motivator. I asked the participants to give clear examples of the connections, and some good examples given.

Decision making is common in sports and can be an important tool for improving education. Especially in team sports, students or athletes need to make decisions almost every second during training or play. This decision-making process is a critical part of the game, which coaches call tactical intelligence. Isabel said:

In sports, we need concentration to see the state of play. Depending on the situation of the game, we need extremely focus. In sports, we develop our decision to answer questions and our ability to make decisions faster. 
Students are excited to play or play and this can provide a perfect environment for producing knowledge through the decision making process.

Another point is that sport helps improve concentration, and this can be very important in the learning process. Isabel said, "If you can focus on the game or the situations, you can go to class and pay attention to the teacher, concentrate on the test ... and feel more relaxed." With concentration, students can think correctly. As [14] explores: "Thinking correctly implies the existence of subjects whose thinking is mediated by objects that provoke and modify the thinking subject" (p.42).

I was very impressed with the comments, and tried to explore further and asked their views on sport at school or sport and academics. Amanda had a good point. Said: "You are playing sport because you like it and have to think about it during sport. This helps you have better thinking. " I asked her to prove it was true. She started laughing and said, "My grades are better now, after I started playing."

Sport keeps you out of trouble - It was a consensus among all participants that sport can block social problems. Young people need to fill their time with enjoyable and important activities. Free time should use to promote knowledge as a very important factor in people's reality because it can promote responsibility and change. Using time for new experiences, such as sports and the arts, is a humanizing experience to change the future. I was wondering if the participants had any ideas for changing their sad situation, and Marco emphasized an important question as follows:

These kids (from the slums) will probably start drug trafficking lives like their friends and siblings ... because they can make money ... but if they have any incentive in the sport ... making some money ... they do not need do that.

Daniel comments this sad reality on. Said: "It is very difficult for children to play sports to go home and see their father drunk or drugged. This is very difficult, and maybe kids give up on sports. "

\subsection{Private School Student Themes}

Unprepared Teachers - The same comment came to private school students. Peter expressed his opinion:

I had learned the same thing all semester ... I feel ... as if I had just ... wasted nine months of my life. Teachers do not care ... teachers teach for money. They do not teach students and are lazy.

School teachers receive a much higher salary compared to public school teachers. They trained and in constant formation. Therefore, this frustration is understandable, because they may be required to perform their responsibilities more effectively. Many students expressed their disappointment and I had the impression that they are very concerned about their studies. I asked if they see that all teachers do not care or are lazy, and Bernardo tried to explain:

In general, not all. I think teachers could find the way ... make it more interesting and fun ... it is just boring ... it is the same day after day. Some teachers try to make the class fun and the classes are the best, but some are doing the same thing repeatedly ... and you do not want to do it anymore.

Teaching is a "kind of passion," and teachers are losing passion because curriculum and quizzes are limiting their freedom and creativity. [14] Wrote: "No nation can assert itself through a savage passion for knowledge without venturing emotionally to constantly reinvent itself and without taking creative risks" (p.37). Instead of being consciously critical, students are suffering from this "lack of passion" because teachers are not promoting critical thinking and school experiences have become boring.

School is boring - The same comment about school also appears by private school students, but for another reason. One factor that makes the school boring is that the teaching process related to the grading system. The idea is to improve education and establish an evaluation system based on test results. Peter said: "It's impossible to get 10 in all subjects as teachers expect ... if you don't get a good grade, you feel more stressed ... so you start disliking school." In fact, private schools are placing too much curricular and budgetary emphasis on standardized tests, without worrying about a broad and meaningful curriculum.

During the interviews, I started talking about how the school could be a better place, and Bruno, a 17-year-old student, expressed his frustration that there were so many rules. He said there many things you cannot do and few things you can do. Represented primarily by teachers, schools are a place where students confuse authority and authoritarianism, freedom and license. One can really see the absurdity of authoritarianism that the whole school space belongs to the educational authorities and teachers [14]. Limited freedom gives students a high level of frustration and school becomes an unfair and unattractive place.

Bernardo showed his frustration when he said, "School is a drug... it's related to a prison." The school space does not belong to the students, and they were in space, but they do not consider themselves to belong to this space. 
Schools should be democratic places to prepare critically thinking citizens. No one fully lives democracy if he interrupted in his right to speak, or if he not engaged, in the struggle to defend that right, which is the right to act [14] and play.

Sport Helping Education - Many students agreed that school is a better place because it has sports. A better place to be is a better place to learn. Ana Julia, a 16-year-old, said: "School is boring and sport makes the difference in having something else to do... it's a good reason to go to school. Sport pushes you... as a motivator. " Many participants expressed their pleasure during PE classes, unlike regular classes. The students showed their frustration with the school and the teachers, and then asked if they feel the same frustration in PE classes. Bernardo said he prefers EF because "it's fun. I am definitely looking forward to my sports class more than my English class or something."

I asked what the sportless school would look like, and Sandro said, "School wouldn't be fun, it would be a little more boring." Douglas, a basketball player, expressed the idea that "school is good because of sport". Therefore, I asked how school could be more fun because of sport, and Sandro said:

In sports, you represent your school in a game, which is good. People who are not in sports can still cheer for school. For me, I want to play college ball and get my education. That is why I need sports

The connection between sport and education is a possibility for college scholars who want sports; however, this is an unrealistic possibility in Brazil, where only a few institutions offer this premise. I asked the participants to give me clear examples of the connections and some good ideas became known. Cecilia summed it up:

Sport is a way to motivate students to pass class because if they do not pass, they will not let you play. Sport has made school more important because you have to pass to play. I think it is fair.

Peter mentioned something important. "Sport is good for achieving academic goals and becoming a better student." In addition, I asked him to explain better, and he said:

I am not sure about everyone else, but we have to emphasize studies, we have to study more. If not, we not supported by our staff and coaches. The coaches support us a lot, because if we have problems in class they will help us.

Cecilia made a point of summarizing sports theory as a motivator at school. She said:

I think the people who succeed on the court are the same people who succeed in the classroom because they have a drive for success no matter what it is. They need to be able to play sports and have to pass, having this pressure, it motivates in the classroom. I think it helps a lot.

Students feel good about sports. They feel motivated to do sport and this motivation transferred to other activities in their routine, such as school. Sandro said sport is important because it helps concentration in class. He said, "Concentration helps us think better about sport or school, where we are focused on something."

In addition, they need to think and make decisions during sport, so this is a critical thinking process that can transferred to regular classes. Sandro said: "We have a better view of the game. For example, if I have the basketball in my hands, I need to pass, but I need to think... the opposite player can "cut" the pass... choose the best way... I need a quick decision". This is another example of critical thinking in the real world. Freire [14] said that real knowledge moves us toward active mobility with creativity and boldness.

The good thing is that most students, parents, and coaches realize this importance and are using it for education. Because of this reality, students are involved in the critical perception of the concrete, not the abstract [17]. They are recognizing its importance and reflecting its opportunities in various dimensions.

Sport keeps you out of trouble - Students explained that sport fills their leisure time instead of using it for drugs and violence, for example. Ana Júlia commented on the social benefits of sports. She said, "Sport is good for keeping people busy during idle time and not doing drugs, for example."

This concept is not new in Brazilian society and the idea is simple but very powerful. Young people with more time available, especially those living in poverty, are more likely to get involved in something problematic or illegal, such as drugs, very common in slums. Bruno commented: "They think about sports and don't have time to think about drugs... they know that if they use drugs, they will have problems in sports... health, right?

This function is not just the responsibility of schools. In addition to school, national policies should emphasize the importance of sport in improving the quality of life and giving individuals freedom to develop their own taste for sport and leisure. The recognized importance of sports for many young people has meant that many sporting opportunities 
have developed in urban regeneration projects, primarily aimed at reducing youth crime, encouraging the positive use of leisure time and capitalizing on the supposed sociopsychological outcomes of sport participation [26].

\section{FINAL CONSIDERATIONS}

Regardless of social, gender or racial background, participation in sport can keep students in school and avoid problems related to downtime such as drugs, violence, pregnancy, boredom, obesity, and lifelong welfare orientation. As sport is a subject that many young people enjoy, schools must increase student participation in sport to promote and expand educational opportunities. Sport is not an end in itself, but it vehicle that can promote educational and social opportunities.

I felt the struggle for social justice during the interview with public school students. Private school students, however, showed no concern about social inequalities. I had to acknowledge that the students in the audience had clear and important comments. They showed their critical and clear view of the problems they were facing and their high expectation of changing this sad reality without conformism. [17] Said that this is the situation awareness procedure, which recognizes the condition and through action prepares men and women to fight the obstacles to their humanization.

Freire intends to promote a theory of action for the oppressed to break free. The result of action that transforms the world and leads to humanization. This theory can applied to sport. Sport can used as a means of releasing and developing knowledge by connecting what children practice and enjoy with what is taught in schools. Students in sports feel free to participate and create. Therefore, sport is action and reaction to transform your world.

Freire's theories can be applied not only to develop physical education classes, but also through interdisciplinary studies, to connect sports within the context of other disciplines, making the school a more attractive place, adapted to what students enjoy.

The sport can be of great importance and very enjoyable for some children. They can use them more academically. Through Freire's principles, an innovative idea can developed, capable of transforming children's reality. The sports circle can used to develop the cultural circle and empower children in schools. In other words, if for social, economic or pedagogical reasons these children are out of the classroom, this may slow down their academic development and, consequently, their chances of breaking free from their oppression. The idea of stimulating education through sport can also to lower dropout rates and improve student performance at school.

\section{REFERENCES}

[1] INEP. (2017). School Census of Basic Education 2016. Statistical Notes. Brasilia DF. February 2017. Available at: <http://download.inep.gov.br/educacao_basica/censo_escolar/notas_estatisticas/2017/notas_estatisticas_censo_escol ar_da_educacao_basica_2016.pdf > Accessed on 22 May 2017.

[2] Dias, Renata. (2017). The importance of sport in education. Available at <http://www.planetaeducacao.com.br/portal/artigo.asp?artigo=790>. Accessed on 14 Aug 2019.

[3] Talamini, J. T; Page, C. H. (1973). Sport and society. An anthology. Boston: Little, Brown and Company.

[4] Mahoney, J; Cairns, R. (1997). Do extracurricular activities protect against early school dropout Development Psychology, 33 (2), 241-253.

[5] Simon, R. (1985). Sport and social values. Englewood Cliffs, NJ: Prentice-Hall.

[6] Snyder, E; Spreitzer, E. (1978). Social aspects of sport. Englewood Cliffs, NJ: Prentice-Hall, INC.

[7] Teich, D. (2002). Where they came from. See Magazine, No. 28A, 36-42.

[8] UNICEF Sport for development and peace. Available

at <http://unesdoc.unesco.org/images/0024/002443/244329EN.pdf〉. Accessed on 17 Aug 2018.

[9] Coakley, J. (1990). Sport in society. Issues and controversies. St. Louis: The C. V. Mosby Company.

[10] Donnelly, P. J. (2002). The role of recreation in promoting social inclusion. Perspectives on social inclusion. (Working papers series). Toronto: The Laidlaw Foundation.

[11] Tubino, M. G. (2001). Social dimensions of sport. Sao Paulo: Cortez Publisher.

[12] Neuenfeldt, D. J. (2008). Esporte, Educação Física e Formação Profissional. Lajeado, RS: Editora Univates.

[13] Allen, J. B. (2003). Social motivation in youth sport. Journal of Sport \& Exercise Psychology, Dec 2003, Vol. 25, Issue 4.

[14]Freire, P. (1998). Pedagogy of freedom. Ethics, democracy and civic courage. Lahman: Rowman \& Littlefield Publishers, Inc.

[15] Rossatto, C. (2001). Social transformation and ¿popular schoolingi in Brazil. Journal of the Association for Childhood Education International, 77, No. 6, 367-374.

[16] Freire, P. (1994). Pedagogy of Hope. Rio de Janeiro: Peace and Earth Press.

[17] Freire, P. (1970). Pedagogy of the oppressed. Sao Paulo: Peace and Earth.

[18] Marshal, C; Rossman, G. (1999). Designing qualitative research (3rd ed.). Thousand Oaks, CA: Sage.

[19] Denzin, N. K; Lincoln, Y. S. (1994). The landscape of qualitative research. Thousand Oaks, CA: Sage Publications. 
[20] Lecompte, M. D; Preissle, J; Tesch, R. (1993). Ethnography and qualitative design in educational research. London: Academic Press.

[21] Creswell, J. W. (1998). Qualitative inquiry and research design. Choosing among five traditions. Thousand Oaks: Sage.

[22] Rossatto, C. (1999). Schooling optimism: A critical analysis of low $i$ and high-achieving students $i$ temporal consciousness in Brazil and United States school settings. Unpublished doctoral dissertation, University of California Los Angeles.

[23] Hantrais, L. (1996). Comparative research methods. Social Research Update, 13.. Available from: http: //www.soc.survey.ac.uk/sru/SRU13.html Accessed 05 May 2019.

[24] Lincoln, Y; Guba, E. (1985) Naturalistic inquiry. Newbury Park, CA: Sage.

[25]Hooks, B. (1994). Teaching to Transgress: Educacion as the Practice of Freedom. New York.

[26] Dunning, E. (1999). Sport matters. Sociological studies of sport, violence and civilization. London: Routledge. 